\title{
Global Pharmaceutical Manufacturing: Association for Accessible Medicines Perspective
}

\author{
David Gaugh, RPh
}

Gaugh's Viewpoint

G eneric medicines play an integral role in health care and enhance patient access to life-saving treatments. Patient safety is the number one priority for the Association for Accessible Medicines (AAM) and its member companies.

Over the last 10 years, generic manufacturers have delivered savings of nearly $\$ 2$ trillion, including $\$ 293$ billion in 2018, to patients and the health care system. ${ }^{1}$ These savings are possible only because of the commitment from manufacturers of generic and biosimilar medicines to quality, safety, and efficacy throughout the pharmaceutical drug supply chain. Patient health and trust go hand in hand, and we do not take that trust for granted.

The United States has one of the safest drug supply chains in the world. ${ }^{2}$ Companies that develop and make medicines, together with the U.S. Food and Drug Administration (FDA), help ensure that all pharmaceuticals meet the same highquality standards regardless of where they are manufactured. All pharmaceuticals, whether generic, biosimilar, or brand, must be manufactured in accordance with rigorous regulatory standards that require high levels of diligence and accompanying documentation. ${ }^{3}$ The FDA and other governmental requirements cover each of the following areas:

- Acquisition of raw materials and drug packaging components, including auditing the manufacturers and suppliers of critical ingredients. ${ }^{4}$

- Testing of active ingredients using qualified equipment and validated methods. ${ }^{5}$

- Constructing and maintaining manufacturing equipment and facilities that have been constructed and maintained to provide sanitary conditions and to protect against contamination. ${ }^{6}$

- Appropriate and documented training of manufacturing personnel. ${ }^{7}$

- Validation of manufacturing processes to ensure that they consistently produce safe, effective, and uniform medicine. ${ }^{8}$

J Manag Care Spec Pharm. 2020;26(5):594-96

Copyright $\odot 2020$, Academy of Managed Care Pharmacy. All rights reserved.
- Thorough contemporaneous documentation of each manufacturing step, with oversight by an employee other than the operator for critical manufacturing steps. ${ }^{9}$

- Taking samples of prescription drugs during the manufacturing process at predetermined intervals and testing the samples for potency and, where appropriate, sterility. ${ }^{10}$

- Maintaining rigid controls over labels placed on drug containers to ensure that the correct labels are placed on every package. ${ }^{11}$

- Thorough testing of prescription drugs before packaging to ensure that they are free of microbial contamination or other defects and that they meet tight specifications for uniformity, potency, and lack of impurities. ${ }^{12}$

- Retention of samples of all manufactured batches of prescription drugs. ${ }^{13}$

- Routine stability testing of the retained samples to ensure that prescription drugs, including biologics, will remain safe and effective and of the quality standards/specifications set by the FDA for the duration of their shelf lives. ${ }^{14}$

- Release of each batch of prescription drugs for distribution only upon review of all batch records and testing data by a quality unit that is independent of manufacturing personnel. ${ }^{15}$

- Continuous oversight by management and regular audits by an independent quality unit of the manufacturer or outside consultants. ${ }^{16}$

- Rigorous documentation of every step in the storage and distribution of manufactured prescription drugs. ${ }^{17}$

- Prompt reporting to the FDA and thorough investigation of any complaints about distributed medicines or any reports that the prescription drugs may have failed to remain safe and effective and of the quality standards/specifications set by the FDA. ${ }^{18}$

When the FDA finds any deviation from the strict standards/specifications of production, the agency takes swift action. Potential actions include requesting that manufacturers recall products, issuing public Warning Letters, imposing import alerts and barring the admission into the United States of violative active pharmaceutical ingredients or finished dosage form, seizing violative medicines, seeking court orders suspending distribution of drug products until the FDA approves 
resumption of operations, and pursuing criminal prosecution of individuals and companies when necessary. ${ }^{19}$

The agency does not hesitate to exercise these powers, taking action not only when prescription drugs are determined to be defective, but when it believes that the system of manufacturing is not sufficient to guarantee that all prescription drugs are safe, effective, and uniform.

AAM stands with the FDA and its work to continually improve oversight of the drug supply pipeline. This includes creation of the Generic Drug User Fee Amendments (GDUFA) of 2012 and its reauthorization in 2017, which included a \$4 billion commitment from the generic drug industry to support the essential work of the agency. ${ }^{20}$ One of the reasons that the generic drug industry supported the user fee program for generic drugs was the imbalance between the frequency of inspections between domestic manufacturers and foreign manufacturers, especially those located in China and India. Legislation at the time required that generic manufacturers located in the United States could expect to be inspected by the FDA at least once every 2 years. In contrast, major suppliers of prescription drugs based in China and India were inspected, on average, less than once every 10 years. GDUFA has significantly increased and continues to augment the funding of FDA's generic drug review and inspection programs. The FDA used a portion of the GDUFA funds to hire more employees to strengthen oversight under GDUFA I implementation; additional employees were added as a result of GDUFA II.

Since that time, GDUFA fees and the foreign drug manufacturer inspections by the FDA that the fees enable have dramatically changed where the FDA has focused its inspection and enforcement efforts. Until 2012, the majority of FDA Warning Letters relating to manufacturing violations issued to mainstream drug manufacturers were based on inspections at facilities located in the United States. ${ }^{21}$ Data for 2016 shows 98\% of FDA Warning Letters were issued to facilities located outside of the United States. The increase in enforcement actions outside of the United States is directly attributable to an increase in the number of FDA inspections. However, it is important to remember that most manufacturers that are inspected are found to be fully compliant with the regulations. ${ }^{22}$

The FDA uses a risk-based inspection strategy, established under the GDUFA I Commitment Letter, to maintain a robust inspections footprint around the world. The FDA has established offices in China and India and uses GDUFA funding to support those offices. The FDA's global inspection efforts are prioritized and focused on facilities in a way to prevent, uncover, and combat data integrity issues and manufacturing problems. Using a risk-based site selection surveillance inspection model, the FDA prioritizes domestic and foreign inspections based on multiple factors carefully selected to appropriately target the agency's resources.
In fiscal year 2017, the FDA conducted 935 inspections of generic drug manufacturing facilities in the United States and around the world that included 547 international inspections and 388 domestic inspections. Moreover, the level of inspections increased between fiscal year 2013 and fiscal year 2017 (5 years) from a total of 721 inspections. ${ }^{23}$ As former FDA Commissioner Scott Gottlieb, MD, noted at the time, "We expect these trends to continue due to resources from GDUFA II." ${ }^{24}$ Thanks to the funding provided by GDUFA, Dr. Gottlieb said, "generic manufacturing and generic drugs are safer than they've ever been. What's changed is that we have better tools now for looking at potential challenges with quality and we have a higher expectation for quality. We're at a place where they're higher quality and the regulatory oversight is, I think, more stringent than it's ever been." 25

$\mathrm{AAM}$ and its members remain committed to ensuring that the FDA continues to have the resources to perform thorough inspections of facilities that manufacture all medicines approved in the U.S. We are pleased that the number of FDA's foreign inspections continue to rise, in no small part based on funding provided by AAM's member companies through GDUFA.

\section{Authors}

DAVID GAUGH, RPh, is Senior Vice President for Sciences and Regulatory Affairs, Association for Accessible Medicines (AAM), and a registered pharmacist.

AUTHOR CORRESPONDENCE: David Gaugh, RPh, can be contacted at 202.249.7111 ordavid.gaugh@accessiblemeds.org.

\section{DISCLOSURES}

No funding supported the writing of this article. The author has nothing to disclosed.

\section{REFERENCES}

1. The Association for Accessible Medicines. The case for competition: 2019 generic drug \& biosimilars access \& savings in the U.S. Report. September 2019. Available at: https://accessiblemeds.org/resources/blog/2019-genericdrug-and-biosimilars-access-savings-us-report. Accessed March 25, 2020.

2. Ashley D, Kopcha M. CDER conversation: assuring drug quality around the globe. U.S. Food and Drug Administration. May 2019. Available at: https://www.fda.gov/drugs/news-events-human-drugs/cder-conversationassuring-drug-quality-around-globe. Accessed March 25, 2020.

3. U.S. Food and Drug Administration. Parts 210, 211, 600-680; Inspection of Biological Drug Products. United States Food and Drug Administration Compliance Program Guidance Manual. Chapter - 45 Biological Drug Products, Section 7345.848. April 1, 2019. Available at: https://www.accessdata.fda.gov/scripts/cdrh/cfdocs/cfcfr/CFRSearch. $\mathrm{cfm}$ ?CFRPart=211\&showFR=1. Accessed March 25, 2020.

4. U.S. Food and Drug Administration. Code of Federal Regulations Title 21 Inspection of Biological Drug Products, United States Food and Drug Administration Compliance Program Guidance Manual. 21 CFR\$211.182. April 1, 2019. Available at: https://www.accessdata.fda.gov/scripts/cdrh/ cfdocs/cfcfr/CFRSearch.cfm?fr=211.82. Accessed March 25, 2020 
5. U.S. Food and Drug Administration. Code of Federal Regulations Title 21. Inspection of Biological Drug Products, United States Food and Drug Administration Compliance Program Guidance Manual. 21 CFR \$211.84. April 1, 2019. Available at: https://www.accessdata.fda.gov/scripts/cdrh/ cfdocs/cfffr/CFRSearch.cfm?fr=211.84. Accessed March 25, 2020.

6. U.S. Food and Drug Administration. Code of Federal Regulations Title 21. \$211.56 (facilities). \$211.65. \$211.67 (equipment). Inspection of Biological Drug Products, United States Food and Drug Administration Compliance Program Guidance Manual. 21 CFR §211.42, 56, 65, 67. April 1, 2019. Available at: https://www.accessdata.fda.gov/scripts/cdrh/cfdocs/cfcfr/ CFRSearch.cfm?CFRPart=211. Accessed March 25, 2020.

7. U.S. Food and Drug Administration. Code of Federal Regulations Title 21. Inspection of Biological Drug Products, United States Food and Drug Administration Compliance Program Guidance Manual. 21 CFR \$211.25. April 1, 2019. Available at: https://www.accessdata.fda.gov/scripts/cdrh/ cfdocs/cfcfr/CFRSearch.cfm?CFRPart=211. Accessed March 25, 2020.

8. U.S. Food and Drug Administration. Code of Federal Regulations Title 21. Inspection of Biological Drug Products, United States Food and Drug Administration Compliance Program Guidance Manual. 21 CFR \$211.100. April 1, 2019. Available at: https://www.accessdata.fda.gov/scripts/cdrh/ cfdocs/cfcfr/CFRSearch.cfm?CFRPart=211. Accessed March 25, 2020

9. U.S. Food and Drug Administration. Code of Federal Regulations Title 21. Inspection of Biological Drug Products, United States Food and Drug Administration Compliance Program Guidance Manual. 21 CFR \$211.101(c); $\S 211.180(a) ; \S 211.186$; \$211.188(b). April 1, 2019. Available at: https://www. accessdata.fda.gov/scripts/cdrh/cfdocs/cfcfr/CFRSearch.cfm?CFRPart=211. Accessed March 25, 2020.

10. U.S. Food and Drug Administration. Code of Federal Regulations Title 21. Inspection of Biological Drug Products, United States Food and Drug Administration Compliance Program Guidance Manual. 21 CFR \$211.110. April 1, 2019. Available at: https://www.accessdata.fda.gov/scripts/cdrh/ cfdocs/cfffr/CFRSearch.cfm?fr=211.110. Accessed March 25, 2020.

11. U.S. Food and Drug Administration. Code of Federal Regulations Title 21. Inspection of Biological Drug Products, United States Food and Drug Administration Compliance Program Guidance Manual. 21 CFR \$211.122; \$211.125; \$211.130; \$211.134. April 1, 2019. Available at: https://www. accessdata.fda.gov/scripts/cdrh/cfdocs/cfcfr/CFRSearch.cfm?CFRPart=211. Accessed March 25, 2020.

12. U.S. Food and Drug Administration. Code of Federal Regulations Title 21 Inspection of Biological Drug Products, United States Food and Drug Administration Compliance Program Guidance Manual. 21 CFR \$211.113; \$211.165; \$211.194. April 1, 2019. Available at: https://www.accessdata.fda. gov/scripts/cdrh/cfdocs/cfcfr/CFRSearch.cfm?CFRPart=211. Accessed March 25, 2020.

13. U.S. Food and Drug Administration. Code of Federal Regulations Title 21. Inspection of Biological Drug Products, United States Food and Drug Administration Compliance Program Guidance Manual. 21 CFR \$211.170(b). April 1, 2019. Available at: https://www.accessdata.fda.gov/ scripts/cdrh/cfdocs/cfffr/CFRSearch.cfm?CFRPart=211. Accessed March 25, 2020.

14. U.S. Food and Drug Administration. Code of Federal Regulations Title 21. Inspection of Biological Drug Products, United States Food and Drug Administration Compliance Program Guidance Manual. 21 CFR \$211.165. April 1, 2019. Available at: https://www.accessdata.fda.gov/scripts/cdrh/ cfdocs/cfffr/CFRSearch.cfm?fr=211.165. Accessed March 25, 2020.
15. U.S. Food and Drug Administration. Code of Federal Regulations Title 21. Inspection of Biological Drug Products, United States Food and Drug Administration Compliance Program Guidance Manual. 21 CFR \$211.22; \$211.142; \$211.167; \$211.192. April 1, 2019. Available at: https://www. accessdata.fda.gov/scripts/cdrh/cfdocs/cfcfr/CFRSearch.cfm?CFRPart=211. Accessed March 25, 2020.

16. U.S. Food and Drug Administration. Code of Federal Regulations Title 21. Inspection of Biological Drug Products, United States Food and Drug Administration Compliance Program Guidance Manual. 21 CFR $\$ 211.180(\mathrm{e}) ;$ \$211.180(f). April 1, 2019. Available at: https://www.accessdata.fda.gov/scripts/cdrh/cfdocs/cfcfr/CFRSearch.cfm?fr=211.180. Accessed March 25, 2020.

17. U.S. Food and Drug Administration. Drug Supply Chain Security Act. Title II of the Drug Quality and Security Act of 2013. 21 CFR \$211.150(b); \$211.196. November 27, 2013. Available at: https://www.fda.gov/drugs/ drug-supply-chain-security-act-dscsa/title-ii-drug-quality-and-security-act. Accessed March 25, 2020.

18. U.S. Food and Drug Administration. Code of Federal Regulations Title 21. Inspection of Biological Drug Products, United States Food and Drug Administration Compliance Program Guidance Manual. 21 CFR \$211.198 April 1, 2019. Available at: https://www.accessdata.fda.gov/scripts/cdrh/ cfdocs/cfcfr/CFRSearch.cfm?fr=211.198. Accessed March 25, 2020.

19. Sharpless N, Plaisier MK, Hermsen CA. Expanding criminal enforcement operations globally to protect public health. FDA's inspections, investigations, and law enforcement operations are led by FDA's Office of Regulatory Affairs. October 17, 2019. Available at: https://www.fda.gov/ news-events/fda-voices-perspectives-fda-leadership-and-experts/expandingcriminal-enforcement-operations-globally-protect-public-health. Accessed March 25, 2020.

20. U.S. Food and Drug Administration. Five-year financial plan for the generic drug user fee amendments. 2019 update. Available at: https://www. fda.gov/media/127003/download. Accessed April 3, 2020.

21. U.S. Food and Drug Administration. Securing the U.S. drug supply chain: oversight of FDA's Foreign Inspection Program. Testimony of Janet Woodcock, MD, Director, Center for Drug Evaluation and Research, before the House Committee on Energy and Commerce, Subcommittee on Oversight and Investigations. December 10, 2019. Available at: https://www. fda.gov/news-events/congressional-testimony/securing-us-drug-supplychain-oversight-fdas-foreign-inspection-program-12102019. Accessed April 3, 2020.

22. U.S. Food and Drug Administration. Facts about the current good manufacturing practices (CGMPs). June 2018. Available at: https://www. fda.gov/drugs/pharmaceutical-quality-resources/facts-about-current-goodmanufacturing-practices-cgmps. Accessed March 25, 2020

23. U.S. Food and Drug Administration. FY2017 performance report to Congress for GDUFA. May 2018. Available at: https://www.fda.gov/ media/113302/download. Accessed March 25, 2020.

24. @SGottliebFDA. Inspectional data from FY2013-FY2017 actually shows an increase in total domestic and foreign generic inspections, read our FY17 GDUFA report. We expect these trends to continue due to resources from GDUFA II. https://t.co/pUiinhtd6x. The \# of inspections we conduct is growing. https://twitter.com/SGottliebFDA/status/1090284678286925824. Posted January 29, 2019.

25. Gottlieb S. Keynote address. The Association for Accessible Medicines. GRx+Biosims 2019; November 4-6, 2019; North Bethesda, MD. 